\title{
Happy Birthday, Journal of Endocrinological Investigation!
}

\author{
L. Bartalena ${ }^{1}$
}

Received: 7 December 2017 / Accepted: 8 December 2017 / Published online: 20 December 2017

(C) Italian Society of Endocrinology (SIE) 2017

The year 2018 is very important for the Journal of Endocrinological Investigation (JEI), because we celebrate its 40th birthday. In fact, the first issue of the JEI, the official journal of the Italian Society of Endocrinology, was published in January 1978 by a group of eminent Italian Endocrinologists. Two of the founders, Prof. Aldo Pinchera and Prof. Giovanni Faglia, were the first two Editors-in-Chief, followed by Prof. Ezio Ghigo and myself.

I am delighted and proud to report that the JEI is thriving. Its impact factor has increased substantially in the last 2 years, is now 2.633, and I am confident that next June it will increase even further for the third consecutive year.

The number of submitted papers doubled in the last 3 years, reaching $>700$ submissions in 2017: they come from all the continents, underscoring that the JEI is truly international. Likewise, in the last 3 years, the number of article downloads has almost doubled each year reaching the peak of about 130,000 downloads, as of October 2017, indicating the continuously increasing worldwide interest and visibility of the JEI. Moreover, to further enhance journal visibility, thanks to Springer's generous support, all the articles included in this celebrative issue will be free to download for 2 months.

We publish high-quality reviews, comments, guidelines and position statements, but also original articles, covering all fields of Endocrinology, including Diabetes, Andrology and Sexual Medicine. The peer-review process is very selective allowing a rejection rate as high as $73 \%$. The present submission-to-first decision time is as low as 26 days, in line with the top journals in this field.

My goal for the next 2 years is to publish manuscripts containing novel information and relevant reviews impacting on our understanding of pathophysiology and management of endocrine disorders.

Renewed and grateful thanks go to all the reviewers who put their time and expertise at the disposition of the Journal, helping me with decisions that were not always easily taken.

I am also utmost grateful to the Editors, all of the Members of the Editorial Board, the Editorial Assistant, the Springer staff for their hard and invaluable work that made these recent achievements possible.

The JEI is a robust and healthy adult, but it will continue to grow.

Happy Birthday, dear Journal of Endocrinological Investigation, from the Editors, the Authors, the Readers, the Staff!

Luigi Bartalena, M.D.

Editor-in-Chief

Journal of Endocrinological Investigation

L. Bartalena

luigi.bartalena@uninsubria.it

1 Endocrine Unit, Department of Medicine and Surgery,

University of Insubria, Varese, Italy 